\title{
Suboptimal use of pelvic lymph node dissection: Differences in guideline adherence between robot-assisted and open radical prostatectomy
}

\author{
Jonas Schiffmann, MD, ${ }^{1,2}$ Alessandro Larcher, MD, ${ }^{1,3,4}$ Maxine Sun; Zhe Tian; Jérémie Berdugo, MD, ${ }^{1,5}$ \\ Ion Leva, MD, ${ }^{1,5}$ Hugues Widmer, MD,6 Jean-Baptiste Lattouf, MD, ${ }^{6}$ Kevin C. Zorn, MD, ${ }^{6}$ Shahrokh F. Shariat, MD; \\ Francesco Montorsi, MD,,3 Markus Graefen, MD, ${ }^{2}$ Fred Saad, MD,; Pierre I. Karakiewicz, MD',6
}

'Cancer Prognostics and Health Outcomes Unit, University of Montreal Health Centre, Montreal, QC, Canada; ${ }^{2}$ Martini-Clinic, Prostate Cancer Centre Hamburg-Eppendorf, Hamburg, Germany; ${ }^{3}$ Urological Research Institute, IRCCS Ospedale San Raffaele, Milan, Italy; ${ }^{4}$ Department of Urology, Vita-Salute San Raffaele University, Milan, Italy; ${ }^{5}$ Department of Pathology, University of Montreal Health Centre, Montreal, QC, Canada; ${ }^{\circ}$ Department of Urology, University of Montreal Health Centre, Montreal, QC, Canada; ${ }^{7}$ Department of Urology, Medical University of Vienna, Vienna, Austria

Cite as: Can Urol Assoc J 2016;10(7-8):269-76. http://dx.doi.org/10.5489/cuaj.3563

\section{Abstract}

Introduction: Our aim was to assess adherence to National Comprehensive Cancer Network (NCCN) and American Urological Association (AUA) guidelines for pelvic lymph node dissection (PLND) at the time of either robot-assisted (RARP) or open radical prostatectomy (ORP).

Methods: We relied on the Surveillance, Epidemiology, and End Results-Medicare linked database and focused on localized prostate cancer $(\mathrm{PCa})$ patients who were treated with either RARP or ORP between October 2008 and December 2009. Categorical and multivariable logistic regression analyses targeted two endpoints: 1) probability of guideline-recommended PLND; and 2) probability of no PLND, when not guideline-recommended.

Results: Among 5268 PCa patients, adherence to NCCN PLND guideline was $56.9 \%$ during RARP and $76.5 \%$ during ORP (odds ratio [OR] 0.4, 95\% confidence interval [CI] 0.3-0.6). AUA PLND guideline adherence was $68.1 \%$ during RARP and $82.4 \%$ during ORP (OR 0.7, 95\% Cl 0.5-0.9). When PLND was not recommended, it was more frequently performed during ORP according to either NCCN (OR 3.7, 95\% Cl 3.5-3.9) or AUA (OR 2.7, 95\% $\mathrm{Cl}$ 2.6-2.8). According to the NCCN guideline, at recommended PLND in ORP patients, $6.3 \%$ harboured lymph node invasion (LNI) (number needed to treat [NNT] 16) vs. 3.2\% at RARP (NNT 31). According to the AUA guideline, at recommended PLND in ORP patients, $12.3 \%$ harboured LNI (NNT 8) vs. 5.1\% RARP (NNT 19). Conclusions: Adherence to NCCN and AUA PLND guidelines was lower during RARP than during ORP when PLND was recommended. The rate of non-recommended PLND was also higher during ORP than during RARP. Technical considerations may be at play.

\section{Introduction}

The recommendations for pelvic lymph node dissection (PLND) differ according to the source of the guideline. ${ }^{1-3}$ The National Comprehensive Cancer Network (NCCN) guideline recommends the use of PLND in patients who have a risk of lymph node invasion $(\mathrm{LNI}) \geq 2 \%{ }^{3,4}$ Conversely, the American Urological Association (AUA) guideline states that PLND should be generally reserved for patients with higher risk of LNI. ${ }^{1}$

Based on the lack of consensus surrounding the indication to carry out PLND during radical prostatectomy (RP) and differences in PLND rates according to the surgical approach,, 5 we compared PLND adherence rates to the NCCN and AUA guidelines in a North American patient cohort and relied on the RARP-specific modifier that became available as of October 2008.

\section{Methods}

\section{Population sources}

The current study relied on the Surveillance, Epidemiology, and End Results (SEER)-Medicare-linked database. The SEER registries cover approximately $28 \%$ of the U.S. population with Medicare administrative data. Medicare covers approximately $97 \%$ of Americans aged $\geq 65$ years. Linkage to the SEER database is complete for approximately $93 \%$ of cases. $^{7}$

\section{Study population}

Overall, 6310 patients with histologically confirmed prostate cancer (PCa) (International Classification of Disease for 
Schiffmann et al.

Oncology [ICD-O] site code 61.9, histologic code 8140) aged 65 years or older treated with RP from October 1 , 2008-December 31, 2009 were identified. This time frame was selected as a specific modifier code for robot-assisted approach (RARP), which was introduced on October 1, 2008 (ICD-9 Clinical Modification [ICD-9-CM] procedure code: 17.42). Patients with unknown clinical characteristics were excluded ( $n=1042)$. This resulted in 5268 assessable patients.

\section{Covariates}

Age, race, population density (urban vs. rural), marital status (married vs. unmarried), 2000 census tract percent with four-year college education (very low $\leq 14.3$; low 14.4-25.4; high 25.5-42.2; and very high $\geq 42.3 \%$ ), 2000 census tract annual median income, region of residence, pathological Gleason score, preoperative prostate-specific antigen (PSA), clinical and pathological tumour stage, nodal stage, surgical volume (low $\leq 2$; intermediate $3-6$; high $\geq 7$ cases/year), and Charlson comorbidity index $(\mathrm{CCl})^{8}$ were assigned.

\section{Statistical analyses}

Our statistical analyses consisted of two steps. First, we quantified the rate of adherence to PLND recommendations according to either the NCCN or AUA guidelines. The contemporary NCCN guideline recommends PLND in patients with a nomogram-calculated LNI risk of $\geq 2 \%{ }^{3,4}$ The AUA guideline recommend a PLND in PCa patients with a PSA $\geq 20 \mathrm{ng} / \mathrm{ml}$ or a PSA between 10 and $20 \mathrm{ng} / \mathrm{ml}$ with a Gleason score $>6 .^{1,2}$

Second, we relied on two separate multivariable logistic regression analyses for predicting PLND when it was recommended according to either the NCCN or AUA guidelines. Then, two additional models were fitted to predict no PLND when it was not recommended according to either NCCN or AUA guidelines. All statistical tests were performed using $R$. All tests were two-sided, with a significance level set at $\mathrm{p}<0.05$.

\section{Results}

\section{Baseline descriptives}

Of 5268 PCa patients, 3123 (59.3\%) were treated with RARP and $2145(40.7 \%)$ were treated with open radical prostatectomy (ORP), respectively. Significant differences between RARP and ORP patients were recorded for several characteristics (Table 1). Most importantly, PLND was significantly less frequent in RARP than in ORP patients (49.8 vs. $72.5 \%$; $<<0.001$ ).

\section{Adherence to guidelines}

First, we examined adherence to the NCCN PLND guideline. PLND was recommended in $73.7 \%$ of RARP and $73.7 \%$ of ORP patients (Fig. 1). PLND was performed in $56.9 \%$ of RARPs and $76.5 \%$ of ORPs when recommended by the NCCN guideline (odds ratio [OR] 0.4, 95\% confidence interval $[\mathrm{Cl}]$ 0.3-0.6; $\mathrm{p}<0.001)$. Conversely, PLND was not recommended by the NCCN guideline in $26.3 \%$ of RARPs and $26.3 \%$ of ORPs. PLND was indeed not performed in $70 \%$ of RARPs and $38.8 \%$ of ORPs (OR 3.7, 95\% Cl 3.5-3.9; $\mathrm{p}<0.001)$. LNI was recorded in $3.2 \%$ of RARP and in $6.3 \%$ of ORP patients when PLND was recommended by the NCCN guideline. The number needed to treat (NNT) was 31 vs. 16 in RARP and ORP patients, respectively (Fig. 1).

Second, we examined adherence to the AUA PLND guideline. According to the AUA guideline, PLND was recommended in $13.8 \%$ of RARP and $17.4 \%$ of ORP patients. PLND was performed in $68.1 \%$ of RARPs and $82.4 \%$ of ORPs when recommended by the AUA guideline (OR 0.7, 95\% Cl 0.5-0.9). Conversely, PLND was not recommended by the AUA guideline in $86.2 \%$ of RARPs and $82.6 \%$ of ORPs. PLND was indeed not performed in $53.1 \%$ of RARPs and $29.6 \%$ of ORPs (OR 2.7, 95\% Cl 2.2-3.3; $\mathrm{p}<0.001)$. LNI was recorded in $5.1 \%$ of RARP and $12.3 \%$ of ORP patients when PLND was recommended by the AUA guideline. The NNT was 19 vs. 8 in RARP and ORP patients, respectively (Fig. 1).

\section{Multivariable logistic regression analyses predicting PLND when PLND is recommended by guidelines}

The first set of multivariable logistic regression analyses focused on predictor variables that are associated with adherence to recommended PLND according to the NCCN guideline. Within these analyses, five variables achieved independent predictor status: surgical approach, region of residence, surgical volume, education, and marital status. Specifically, patients treated by high-volume surgeons were more likely to undergo PLND when recommended than those treated by low-volume surgeons (OR 1.3, 95\% Cl 1.0-1.7; $p=0.048)$. Additionally, patients residing on the Pacific coast (OR 1.3, 95\% Cl 1.1-1.7; $p=0.002$ ) were more likely to undergo PLND when recommended than those residing in the East. Similarly, patients from the high education category were more likely to undergo PLND when recommended than those from the very low education category (OR 1.5, 95\% Cl 1.0-2.1; p=0.04). Conversely, patients treated with RARP were less likely to undergo PLND when recommended than ORP patients (OR 0.4, 95\% Cl 0.3-0.5; $\mathrm{p}<0.001)$. Finally, unmarried patients were also less likely to undergo PLND when recommended compared to those who were married (OR 0.8, 95\% Cl 0.6-0.96; $\mathrm{p}=0.03$ ) (Table 2). 


\begin{tabular}{|c|c|c|c|c|}
\hline Parameter & $\begin{array}{l}\text { Overall } \\
n=5268\end{array}$ & $\begin{array}{c}\text { ORP } \\
n=2145(40.7 \%)\end{array}$ & $\begin{array}{c}\text { RARP } \\
\mathrm{n}=3123(59.3 \%)\end{array}$ & $p$ value \\
\hline \multicolumn{5}{|l|}{ Patient age, years } \\
\hline Mean (median) & $69.1(68.0)$ & $69.2(68.0)$ & $69.0(68.0)$ & 0.1 \\
\hline IQR & $66.0-71.0$ & $66.0-71.0$ & $66.0-71.0$ & \\
\hline Range & $65-80$ & $65-80$ & $65-80$ & \\
\hline \multicolumn{5}{|c|}{ Patient age categories, n (\%) } \\
\hline $65-66$ & $1351(25.6)$ & $544(25.4)$ & 807 (25.8) & 0.3 \\
\hline $67-68$ & $1364(25.9)$ & $541(25.2)$ & $823(26.4)$ & \\
\hline $69-71$ & $1373(26.1)$ & $551(25.7)$ & $822(26.3)$ & \\
\hline$\geq 72$ & $1180(22.4)$ & $509(23.7)$ & $671(21.5)$ & \\
\hline \multicolumn{5}{|l|}{ Race, n (\%) } \\
\hline White & $4337(82.3)$ & $1747(81.4)$ & $2590(82.9)$ & 0.08 \\
\hline Black & $456(8.7)$ & $208(9.7)$ & $248(7.9)$ & \\
\hline Other & $475(9.0)$ & $190(8.9)$ & $285(9.1)$ & \\
\hline \multicolumn{5}{|l|}{ Marital status, n (\%) } \\
\hline Married & $4154(78.9)$ & $1672(77.9)$ & $2482(79.5)$ & 0.2 \\
\hline Unmarried & $1114(21.1)$ & $473(22.1)$ & $641(20.5)$ & \\
\hline \multicolumn{5}{|c|}{ Income in US\$/year, n (\%) } \\
\hline$\leq 38012$ & $1300(24.7)$ & $644(30.1)$ & $656(21.0)$ & $<0.001$ \\
\hline $38013-50954$ & $1332(25.3)$ & $571(26.6)$ & $761(24.4)$ & \\
\hline $50955-69389$ & $1321(25.1)$ & $513(23.9)$ & $808(25.9)$ & \\
\hline$\geq 69390$ & $1315(25.0)$ & $417(19.4)$ & $898(28.8)$ & \\
\hline \multicolumn{5}{|l|}{ Education, n (\%) } \\
\hline Very low & $1303(24.7)$ & $632(29.5)$ & $671(21.5)$ & $<0.001$ \\
\hline Low & $1319(25.0)$ & 575 (26.8) & $744(23.8)$ & \\
\hline High & $1331(25.3)$ & $505(23.5)$ & $826(26.4)$ & \\
\hline Very high & $1315(25.0)$ & $433(20.2)$ & $882(28.2)$ & \\
\hline \multicolumn{5}{|c|}{ Population density, n (\%) } \\
\hline Urban & $4626(87.8)$ & $1806(84.2)$ & $2820(90.3)$ & $<0.001$ \\
\hline Rural & $642(12.2)$ & $339(15.8)$ & $303(9.7)$ & \\
\hline \multicolumn{5}{|c|}{ Region of residence, n (\%) } \\
\hline East & $1728(32.8)$ & $676(31.5)$ & 1052 (33.7) & $<0.001$ \\
\hline Northern plains & $538(10.2)$ & $193(9.0)$ & $345(11.0)$ & \\
\hline Pacific coast & $2637(50.1)$ & 1017 (47.5) & $1620(51.9)$ & \\
\hline Southwest & $365(6.9)$ & $259(12.1)$ & $106(3.4)$ & \\
\hline \multicolumn{5}{|c|}{ Charlson comorbidity index, $\mathrm{n}(\%)$} \\
\hline 0 & $3684(69.9)$ & 1477 (68.9) & $2207(70.7)$ & 0.4 \\
\hline 1 & $528(10.0)$ & $214(10.0)$ & $314(10.1)$ & \\
\hline 2 & $560(10.6)$ & $241(11.2)$ & $319(10.2)$ & \\
\hline$\geq 3$ & $496(9.4)$ & $213(9.9)$ & $283(9.1)$ & \\
\hline \multicolumn{5}{|c|}{ Preoperative serum PSA, ng/ml } \\
\hline Mean (median) & $8.4(5.9)$ & $8.9(6.1)$ & $8.1(5.8)$ & $<0.001$ \\
\hline IQR & $4.5-8.6$ & $4.6-9.0$ & $4.5-8.3$ & \\
\hline Range & $0.1-98$ & $0.1-98$ & $0.1-98$ & \\
\hline \multicolumn{5}{|c|}{ Preoperative serum PSA (ng/ml), $\mathrm{n}(\%)$} \\
\hline$<10$ & $4298(81.6)$ & $1691(78.8)$ & 2607 (83.5) & $<0.001$ \\
\hline $10-20$ & $684(13.0)$ & $308(14.4)$ & $376(12.0)$ & \\
\hline$>20$ & $286(5.4)$ & $146(6.8)$ & $140(4.5)$ & \\
\hline \multicolumn{5}{|c|}{ Clinical tumour stage, n (\%) } \\
\hline$\leq \mathrm{cT} 2 \mathrm{a}$ & 4588 (87.1) & 1817 (84.7) & 2771 (88.7) & $<0.001$ \\
\hline cT2b-cT2c & $540(10.3)$ & $257(12.0)$ & $283(9.1)$ & \\
\hline$\geq \mathrm{cT3a}$ & $140(2.7)$ & 71 (3.3) & $69(2.2)$ & \\
\hline
\end{tabular}

IQR: interquartile range; ORP: open radical prostatectomy; PSA: prostate-specific antigen; RARP: robot-assisted radical prostatectomy; SEER: Surveillance, Epidemiology, and End Results.

The second set of multivariable logistic regression analyses focused on variables that are associated with adherence to recommended PLND according to the AUA guideline.
Within these analyses, two variables achieved independent predictor status: surgical approach and region of residence. Specifically, patients treated with RARP were less likely to 
Schiffmann et al.

\begin{tabular}{|c|c|c|c|c|}
\hline Parameter & $\begin{array}{l}\text { Overall } \\
n=5268\end{array}$ & $\begin{array}{c}\text { ORP } \\
n=2145(40.7 \%)\end{array}$ & $\begin{array}{c}\text { RARP } \\
\mathrm{n}=3123(59.3 \%)\end{array}$ & p value \\
\hline \multicolumn{5}{|l|}{ Pelvic lymph node dissection, n (\%) } \\
\hline Not performed & $2157(40.9)$ & $590(27.5)$ & $1567(50.2)$ & $<0.001$ \\
\hline Performed & $3111(59.1)$ & $1555(72.5)$ & $1556(49.8)$ & \\
\hline \multicolumn{5}{|l|}{ Gleason score, n (\%) } \\
\hline$\leq 6$ & $1524(28.9)$ & $660(30.8)$ & $864(27.7)$ & $<0.001$ \\
\hline 7 & $2916(55.4)$ & $1118(52.1)$ & $1798(57.6)$ & \\
\hline $8-10$ & $828(15.7)$ & $367(17.1)$ & $461(14.8)$ & \\
\hline \multicolumn{5}{|l|}{ Pathological tumour stage, $\mathrm{n}(\%)$} \\
\hline pT2 & $3595(68.2)$ & $1463(68.2)$ & $2132(68.3)$ & $<0.001$ \\
\hline рT3 & $1281(24.3)$ & $486(22.7)$ & $795(25.5)$ & \\
\hline pT4 & $53(1.0)$ & $28(1.3)$ & $25(0.8)$ & \\
\hline Missing & $339(6.4)$ & $168(7.8)$ & $171(5.5)$ & \\
\hline \multicolumn{5}{|l|}{ Nodal stage, n (\%) } \\
\hline $\mathrm{pNO} / \mathrm{NX}$ & $5146(97.7)$ & $2068(96.4)$ & $3078(98.6)$ & $<0.001$ \\
\hline $\mathrm{pN} 1$ & $122(2.3)$ & $77(3.6)$ & $45(1.4)$ & \\
\hline $\begin{array}{l}\text { Organ-confined tumour ( } \leq \mathrm{pT} 2, \mathrm{~N} 0 / \\
\mathrm{NX}), \mathrm{n}(\%)\end{array}$ & $3567(67.7)$ & $1444(67.3)$ & $2123(68.0)$ & 0.6 \\
\hline \multicolumn{5}{|l|}{ Surgical volume tertiles, n (\%) } \\
\hline Low & 759 (33.9) & $345(35.2)$ & $441(32.8)$ & $<0.001$ \\
\hline Intermediate & $723(32.2)$ & $402(41.0)$ & $321(25.5)$ & \\
\hline High & 760 (33.9) & $234(23.9)$ & $526(41.7)$ & \\
\hline
\end{tabular}

Table 2. Multivariable logistic regression analyses A: adherence to PLND recommendation according to NCCN guideline; B: adherence to PLND recommendation according to AUA guideline, in $\mathbf{5 2 6 8}$ patients treated with either RARP or ORP for localized prostate cancer between October 1, 2008 and December 31, 2009 within the SEER-Medicare-linked database

Multivariable analyses $\mathrm{A}$

Adherence to PLND recommendation according to NCCN guideline: PLND when PLND is recommended
Multivariable analyses $B$

Adherence to PLND recommendation according to AUA guideline: PLND when PLND is recommended

\begin{tabular}{|c|c|c|c|c|}
\hline & OR (95\% Cl) & p value & OR (95\% Cl) & p value \\
\hline \multicolumn{5}{|l|}{ Surgical approach } \\
\hline ORP & 1 (ref.) & & 1 (ref.) & \\
\hline RARP & $0.4(0.3-0.5)$ & $<0.001$ & $0.2(0.1-0.5)$ & $<0.001$ \\
\hline \multicolumn{5}{|c|}{ Region of residence } \\
\hline East & 1 (ref.) & & 1 (ref.) & \\
\hline Northern plains & $1.3(0.9-1.9)$ & 0.1 & $4.6(1.4-15.2)$ & 0.01 \\
\hline Pacific coast & $1.3(1.1-1.7)$ & 0.02 & $1.2(0.6-2.4)$ & 0.6 \\
\hline Southwest & $0.9(0.5-1.5)$ & 0.6 & $0.6(0.2-1.6)$ & 0.3 \\
\hline \multicolumn{5}{|l|}{ Surgical volume } \\
\hline Low & 1 (ref.) & & 1 (ref.) & \\
\hline Intermediate & $1.2(0.9-1.5)$ & 0.2 & $1.4(0.7-2.8)$ & 0.4 \\
\hline High & $1.3(1.0-1.7)$ & 0.048 & $1.2(0.6-2.5)$ & 0.5 \\
\hline \multicolumn{5}{|l|}{ Education } \\
\hline Very low & 1 (ref.) & & 1 (ref.) & \\
\hline Low & $1.1(0.8-1.5)$ & 0.6 & $0.7(0.3-1.5)$ & 0.4 \\
\hline High & $1.5(1.0-2.1)$ & 0.04 & $2.1(0.8-5.4)$ & 0.1 \\
\hline Very high & $1.4(0.9-2.1)$ & 0.2 & $2.9(0.8-9.9)$ & 0.1 \\
\hline \multicolumn{5}{|l|}{ Marital status } \\
\hline Married & 1 (ref.) & & 1 (ref.) & \\
\hline Unmarried & $0.8(0.6-0.96)$ & 0.03 & $0.6(0.3-1.1)$ & 0.1 \\
\hline
\end{tabular}




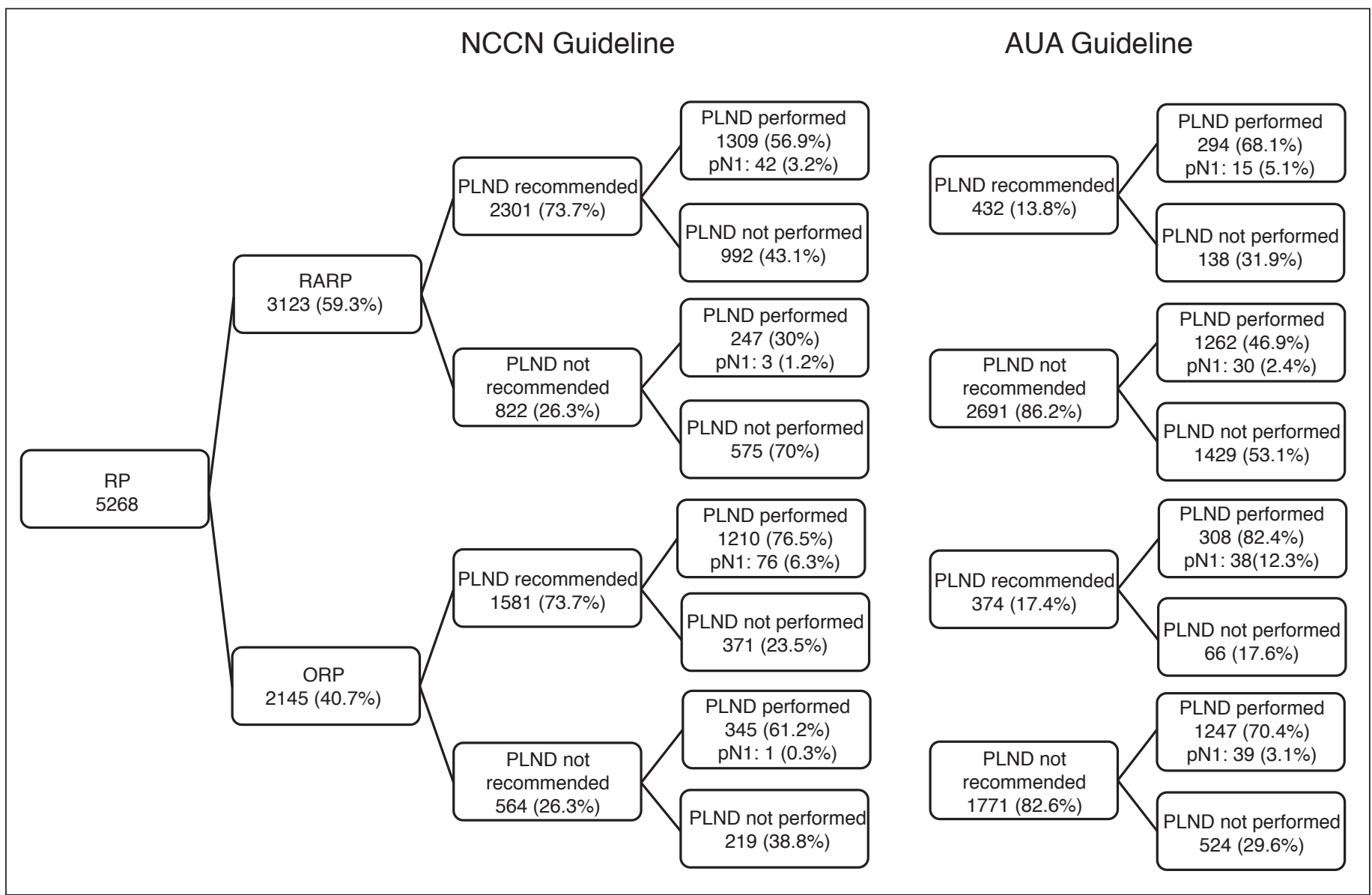

Fig. 1. Flow chart representing surgical approach (robot-assisted vs. open radical prostatectomy) in 5268 patients; pelvic lymph node dissection (PLND) recommendation (National Comprehensive Cancer Network, American Urological Association) and the PLND status (performed vs. not performed).

undergo PLND when recommended than those treated with ORP (OR 0.2, 95\% Cl 0.1-0.5; $\mathrm{p}<0.001)$. Finally, patients residing in the Northern plains were more likely to undergo PLND when recommended than those residing in the East (OR 4.6, 95\% Cl 1.4-15.2; $\mathrm{p}=0.01$ ) (Table 2).

\section{Multivariable logistic regression models predicting absence of PLND when PLND is not recommended by guidelines}

The third set of multivariable logistic regression analyses focused on predicting no PLND when it was not recommended according to the NCCN guideline. Within these analyses, two variables achieved independent predictor status: surgical approach and surgical volume. Specifically, RARP patients were more likely to not undergo PLND when not recommended (OR 5.0, 95\% Cl 3.4-7.7; $p<0.001$ ). Finally, patients treated by high-volume surgeons were less likely to not undergo PLND when not recommended than those treated by low-volume surgeons (OR $0.5,95 \% \mathrm{Cl}$ 0.3-0.8; $\mathrm{p}=0.007$ ) (Table 3).

The final multivariable logistic regression analyses focused on predicting no PLND when it was not recommended according to the AUA guideline. Within these analyses, three variables achieved independent predictor status: surgical approach, region of residence, and surgical volume. Specifically, patients treated with RARP were more likely to not undergo PLND when not recommended than ORP patients (OR 3.0, 95\% Cl 2.4-3.7; $p<0.001$ ). Conversely, patients residing at the Pacific coast were less likely to not undergo PLND when not recommended than those residing in the East (OR 0.8, 95\% $\mathrm{Cl} \mathrm{0.6-1.0;} \mathrm{p}=0.02$ ). Finally, patients treated by high-volume surgeons were also less likely to not undergo PLND when not recommended than those treated by low-volume surgeons (OR 0.7, 95\% Cl 0.6-0.9; $\mathrm{p}=0.003$ ) (Table 3).

\section{Discussion}

Recommendations for PLND at RP differ according to the source of the guideline. ${ }^{1,3}$ Additionally, PLND rates might vary according to surgical approach. ${ }^{5,6,9}$ The objective of the present study was to assess differences in NCCN and 
Schiffmann et al.

AUA guideline adherence to PLND recommendations during RARP or ORP. Our analyses detected several important findings.

First, according to the NCCN guideline, the rates of PLND recommendation were not significantly different between RARP and ORP patients (73.7 vs. 73.7\%; $p=1.0$ ). However, RARP patients less frequently underwent PLND when recommended (56.9 vs. 76.5\%, OR 0.4; $p<0.001$ ). Conversely, RARP patients more frequently did not undergo PLND when PLND was not recommended (70 vs. $38.8 \%$, OR 3.7; $\mathrm{p}<0.001)$.

Second, according to the AUA guideline, the rates of PLND recommendation were significantly lower for RARP than ORP patients (13.8 vs. $17.4 \%$; $p=0.001$ ). Despite this difference, RARP patients underwent PLND less frequently than ORP patients when recommended (68.1 vs. $82.4 \%$, OR $0.7 ; p=0.01$ ). As for NCCN guidelines, RARP patients more frequently did not undergo PLND when not recommended than ORP patients (53.1 vs. 29.6\%, OR 2.7; $\mathrm{p}<0.001$ ).

When the first and second points are taken together, they indicate that the threshold for PLND varies according to guideline. The NCCN guideline is more stringent and leads to more frequent PLND then the AUA guideline. However, regardless of the guideline, RARP patients were invariably less frequently treated with PLND than ORP patients.

Third, we examined the rates of $\mathrm{LNI}$ according to recommended rates of PLND and found higher rates and lower NNT values when the AUA guideline was followed. However, such trade-off was associated with higher number of missed patients with LNI. In consequence, clinicians need to decide which approach is preferred.

Fourth, we examined predictors of recommended PLND and predictors of no PLND when not recommended by guidelines. In these analyses, surgical approach (ORP) was invariably associated with higher PLND rates. The region of residence also affected PLND rates. Pacific coast residents were more likely to undergo PLND when recommended by the NCCN guideline. Similarly, patients from Northern plains more frequently underwent PLND when it was recommended by the AUA guideline. Conversely, patients from the Pacific coast were less likely not to have a PLND when it was not recommended according to the AUA guideline. Surgical volume affected the rate of recommended PLND and, invariably, no PLND when not recommended according to guidelines. High-volume surgeons were more likely to perform a PLND when recommended according to the

Table 3. Multivariable logistic regression analyses C: adherence to no PLND recommendation according to NCCN guidelines; and D: adherence to no PLND recommendation according to AUA guideline in 5268 patients treated with either RARP or ORP for localized prostate cancer between October 1, 2008 and December 31, 2009 within the SEER-Medicare-linked database

\begin{tabular}{|c|c|c|c|c|}
\hline & \multicolumn{2}{|c|}{$\begin{array}{c}\text { Multivariable analyses C } \\
\text { Adherence to no PLND recommendation according } \\
\text { to NCCN guideline: No PLND when PLND not } \\
\text { recommended }\end{array}$} & \multicolumn{2}{|c|}{$\begin{array}{l}\text { Multivariable analyses D } \\
\text { Adherence to no PLND recommendation } \\
\text { according to AUA guideline: No PLND } \\
\text { when PLND not recommended }\end{array}$} \\
\hline & OR (95\% CI) & p value & OR $(95 \% \mathrm{CI})$ & $p$ value \\
\hline \multicolumn{5}{|l|}{ Surgical approach } \\
\hline ORP & 1 (ref.) & & & \\
\hline RARP & $5.0(3.4-7.7)$ & $<0.001$ & $<0.001$ & $<0.001$ \\
\hline \multicolumn{5}{|l|}{ Region of residence } \\
\hline East & 1 (ref.) & & 1 (ref.) & \\
\hline Northern plains & $1.4(0.8-2.7)$ & 0.3 & $1.0(0.7-1.4)$ & 1.0 \\
\hline Pacific coast & $1.0(0.7-1.6)$ & 0.9 & $0.8(0.6-1.0)$ & 0.02 \\
\hline Southwest & $2.0(0.9-4.3)$ & 0.07 & $1.4(0.9-2.2)$ & 0.1 \\
\hline \multicolumn{5}{|l|}{ Surgical volume } \\
\hline Low & 1 (ref.) & & 1 (ref.) & \\
\hline Intermediate & $1.0(0.6-1.7)$ & 0.9 & $0.9(0.7-1.1)$ & 0.4 \\
\hline High & $0.5(0.3-0.8)$ & 0.007 & $0.7(0.6-0.9)$ & 0.003 \\
\hline \multicolumn{5}{|l|}{ Education } \\
\hline Very low & 1 (ref.) & & 1 (ref.) & \\
\hline Low & $0.8(0.5-1.4)$ & 0.5 & $0.8(0.6-1.1)$ & 0.2 \\
\hline High & $0.9(0.5-1.7)$ & 0.7 & $0.8(0.6-1.1)$ & 0.2 \\
\hline Very high & $0.9(0.4-1.8)$ & 0.7 & $0.8(0.6-1.2)$ & 0.4 \\
\hline \multicolumn{5}{|l|}{ Marital status } \\
\hline Married & 1 (ref.) & & 1 (ref.) & \\
\hline Unmarried & $1.4(0.9-2.3)$ & 0.1 & $1.3(1.0-1.7)$ & 0.03 \\
\hline $\begin{array}{l}\text { All analyses were also adj } \\
(0,1,2, \geq 3) \text {, race (White, BI } \\
\text { Urological Association; CI: } \\
\text { robot-assisted radical pros }\end{array}$ & $\begin{array}{l}\text { n, population density (rural } \\
\text { ategories }(\leq 38012,38013-4 \\
\text { onal Comprehensive Cance } \\
\text { pidemiology, and End Resu }\end{array}$ & $\begin{array}{l}\text { categories }(65-66,67 \\
\geq 69,390 \text { US } \$ \text { ), which } \\
\text { tio; ORP: open radica }\end{array}$ & $\begin{array}{l}\text { 69-71, } \geq 72 \text { years), Charl } \\
\text { to reach insignificant } p \\
\text { statectomy; PLND: pelv }\end{array}$ & $\begin{array}{l}\text { ty index categories } \\
\text { AUA: American } \\
\text { dissection; RARP: }\end{array}$ \\
\hline
\end{tabular}


NCCN guideline. Conversely, high-volume surgeons were less likely to not perform PLND when it was not recommended by either the NCCN or AUA guidelines. Education category affected PLND rates; patients from the high education category were more likely to undergo PLND than those from the very low education category when PLND was recommended according to the NCCN guideline. Finally, marital status also affected PLND rates; unmarried patients were less likely to undergo PLND when recommended according to the NCCN guideline. Conversely, those patients were more likely to not undergo PLND when not recommended according to the AUA guideline. Together, these results show that besides surgical approach, other variables, such as patient characteristics or surgeon volume, may affect PLND rates.

Our results are in agreement with other studies that examined rates of PLND according to surgical approach. 5,6,10-14 To the best of our knowledge, the current study represents the only contemporary assessment of adherence to NCCN and AUA guidelines that differentiated according to surgical approach and relied on the RARP-specific modifier that became available as of October 2008.

Despite its strengths, our study has limitations. First, our cohort exclusively originates from the Medicare database, with an age distribution of over 65 years. The results might not be generalizable to younger patients. Second, due to a lack of detailed information from SEER-Medicare-derived analyses, we relied on pathological Gleason score. Since high rates of upgrading were recorded between clinical and pathological Gleason score, ${ }^{15}$ a corresponding bias might exist in our analyses. Finally, other limitations known to affect SEER-Medicare-derived analyses are also operational, for example, use of claims data or lack of detailed parameters that are included in prospective trials.

\section{Conclusion}

Our data indicate that adherence to either NCCN or AUA guidelines remains suboptimal. The urological community should be sensitized about the staging impact of PLND ${ }^{16-19}$ and possible elimination of micrometastases, $17,20-22$ especially during RARP. ${ }^{23}$ On the other hand, it is also important to notice that a non-negligible percentage was exposed to the potential harm of PLND ${ }^{9,24,25}$ when it was not recommended. Followup studies are needed in more recently treated patients.

Competing interests: Dr. Lattouf has been an Advisory Board member for AbbVie, Amgen, Astellas, Novartis, and Pfizer; and has received an educational grant from Janssen. Dr. Zorn is a consultant and an Advisory Board member for Boston Scientific. Dr. Saad has been an Advisory Board member for Janssen and Sanofi; and has received research funding, as well as honoraria from Sanofi. The remaining authors report no competing personal or financial interests.
This paper has been peer-reviewed.

\section{References}

1. Thompson I, Thrasher JB, Aus $G$, et al. Guideline for the management of clinically localized prostate cancer: 2007 update. J Urol 2007;177:2106-31. http://dx.doi.org/10.1016/i.juro.2007.03.003

2. Carroll P, Coley C, McLeod D, et al. Prostate-specific antigen best practice policy—part II: Prostate cancer staging and post-treatment followup. Urology 2001;57:225-9. http://dx.doi.org/10.1016/ S0090-4295(00)00994-8

3. Mohler JL, Kantoff PW, Armstrong AJ, et al. Prostate cancer, version 2.2014. J Natl Compr Canc Netw 2014;12:686-718

4. Cagiannos I, Karakiewicz P, Eastham JA, et al. A preoperative nomogram identifying decreased risk of positive pelvic lymph nodes in patients with prostate cancer. J Urol 2003;170:1798-1803. http://dx.doi.org/10.1097/01.ju.0000091805.98960.13

5. Feifer AH, Elkin EB, Lowrance WT, et al. Temporal trends and predictors of pelvic lymph node dissection in open or minimally invasive radical prostatectomy. Cancer 2011;117: 3933-42. http://dx.doi. org/10.1002/cncr.25981

6. Gandaglia G, Trinh QD, Hu JC, et al. The impact of robot-assisted radical prostatectomy on the use and extent of pelvic lymph node dissection in the "post-dissemination" period. Eur J Surg Oncol 2014;40:10806. http://dx.doi.org/10.1016/i.ejso.2013.12.016

7. Warren JL, Klabunde CN, Schrag D, et al. Overview of the SEER-Medicare data: Content, research applications, and generalizability to the United States elderly population. Medical Care 2002;40:IV-3-18. http://dx.doi.org/10.1097/00005650-200208001-00002

8. Klabunde CN, Potosky AL, Legler JM, et al. Development of a comorbidity index using physician claims data. J Clin Epidemiol 2000;53:1258-17. http://dx.doi.org/10.1016/S0895-4356(00)00256-0

9. Schiffmann J, Haese A, Leyh-Bannurah SR, et al. Adherence of the indication to European Association of Urology guideline recommended pelvic lymph node dissection at a high-volume centre: Differences between open and robot-assisted radical prostatectomy. Eur I Surg Oncol 2015;41:1547-53. http://dx.doi.org/10.1016/i.ejso.2015.05.008

10. Briganti A, Bianchi $M$, Sun $M$, et al. Impact of the introduction of a robotic training program on prostate cancer stage migration at a single tertiary referral centre. BJU Int 2013;111:1222-30. http://dx.doi. org/10.1111/i.1464-410X.2012.11464.x

11. Abdollah F, Abdo A, Sun M, et al. Pelvic lymph node dissection for prostate cancer: Adherence and accuracy of the recent guidelines. Int J Urol 2013;20:405-10. http://dx.doi.org/10.1111/j.14422042.2012.03171.x

12. Hu JC, Prasad SM, Gu X, et al. Determinants of performing radical prostatectomy pelvic lymph node dissection and the number of lymph nodes removed in elderly men. Urology 2011;77:402-6. http:// dx.doi.org/10.1016/i.urology.2010.05.015

13. Cooperberg MR, Kane CJ, Cowan JE, et al. Adequacy of lymphadenectomy among men undergoing robotassisted laparoscopic radical prostatectomy. BJU Int 2010;105:88-92. http://dx.doi.org/10.1111/ j.1464-410X.2009.08699.x

14. Schiffmann J, Haese A, Leyh-Bannurah SR, et al. Adherence of the indication to European Association of Urology guideline recommended pelvic lymph node dissection at a high-volume centre: Differences between open and robot-assisted radical prostatectomy. Eur J Surg Oncol 2015;41:1547-53. http:// dx.doi.org/10.1016/i.ejso.2015.05.008

15. Schiffmann J, Wenzel P, Salomon G, et al. Heterogeneity in D'Amico classification-based low-risk prostate cancer: Differences in upgrading and upstaging according to active surveillance eligibility. Urol Oncol 2015;33:329. http://dx.doi.org/10.1016/j.urolonc.2015.04.004

16. Masterson TA, Bianco FJ Jr, Vickers AJ et al. The association between total and positive lymph node counts, and disease progression in clinically localized prostate cancer. J Urol 2006; 175:1320-4; discussion 1324-5. http://dx.doi.org/10.1016/S0022-5347(05)00685-3

17. Joslyn SA and Konety BR: Impact of extent of lymphadenectomy on survival after radical prostatectomy for prostate cancer. Urology 2006; 68: 121-5. http://dx.doi.org/10.1016/i.urology.2006.01.055

18. Allaf ME, Palapattu GS, Trock BJ, et al. Anatomical extent of lymph node dissection: Impact on men with clinically localized prostate cancer. J Urol 2004;172:1840-4. http://dx.doi.org/10.1097/01. ju.0000140912.45821.1d

19. Pautler S: Lymph node dissection in radical prostatectomy: What nodes? Can Urol Assoc J 2011;5:260. http://dx.doi.org/10.5489/cuaj.11145

20. Bader $\mathrm{P}$, Burkhard $\mathrm{FC}$, Markwalder $\mathrm{R}$, et al. Disease progression and survival of patients with positive lymph nodes after radical prostatectomy. Is there a chance of cure? J Urol 2003;169:849-54. http:// dx.doi.org/10.1097/01.ju.0000049032.38743.c7 
Schiffmann et al.

21. Daneshmand S, Quek ML, Stein JP, et al. Prognosis of patients with lymph node positive prostate cancer following radical prostatectomy: Long-term results. J Urol 2004;172:2252-5. http://dx.doi. org/10.1097/01.ju.0000143448.04161.cc

22. Wagner $M$, Sokoloff $M$, Daneshmand $S$. The role of pelvic lymphadenectomy for prostate cancer - therapeutic? J Urol 2008; 179:408-13. htrp://dx.doi.org/10.1016/i.juro.2007.09.027

23. Di Pierro GB, Grande P, Wirth JG, et al. Extended pelvic lymph node dissection at the time of robot-assisted radical prostatectomy: Impact of surgical volume on efficacy and complications in a single-surgeon series. Can Urol Assoc J 2015; 9:107-13. http://dx.doi.org/10.5489/cuai.2485

24. Clark T, Parekh DJ, Cookson MS, et al. Randomized prospective evaluation of extended vs. limited lymph node dissection in patients with clinically localized prostate cancer. J Urol 2003;169:145-7; discussion 147-8. http://dx.doi.org/10.1016/S0022-5347(05)64055-4

25. Park SC, Lee JW, Park SA, et al. The deep vein thrombosis caused by lymphocele after endoscopic extraperitoneal radical prostatectomy and pelvic lymph node dissection. Can Urol Assoc J 2011;5:E40-3

Correspondence: Dr. Jonas Schiffmann, Department of Urology, Academic Hospital Braunschweig, Braunschweig, Germany; i.schiffmann@klinikum-braunschweig.de

\section{${ }^{\mathrm{X}} \mathrm{XGEVA}$ (denosumab)}

Indication and clinical use:

- XGEVA ${ }^{\circledR}$ is indicated for reducing the risk of developing skeletal-related events (SREs) in patients with bone metastases from breast cancer, prostate cancer, non-small cell lung cancer, and other solid tumours.

- Not indicated for reducing the risk of developing skeletal-related events in patients with multiple myeloma.

- Not indicated for reducing the risk of developing skeletal-related events in pediatric patients.

Contraindications:

-In patients with pre-existing hypocalcemia, which must be corrected prior to initiation.

\section{Most serious warnings and precautions:}

Osteonecrosis of the jaw (ONJ): In clinical trials, the incidence of ONJ was higher with longer duration of exposure. In patients with risk factors for ONJ, an individual risk/benefit assessment should be performed before initiating therapy with XGEVA. An oral exam should be performed and a dental exam with appropriate preventive dentistry is recommended prior to treatment with XGEVA, especially in patients with risk factors for ONJ. Avoid invasive dental procedures while receiving XGEVA. In patients who develop ONJ during treatment with XGEVA, a temporary interruption of treatment should be considered based on individual risk/benefit assessment until the condition resolves.

\section{Other relevant warnings and precautions:}

-Do not use concurrently with Prolia

-Do not use concurrently with bisphosphonates

- Hypocalcemia has been reported (including severe symptomatic hypocalcemia and fatal cases). Monitor calcium prior to the initial dose, within two weeks after the initial dose, and if suspected symptoms of hypocalcemia occur. Administer adequate calcium, vitamin $\mathrm{D}$, and magnesium, as necessary. If hypocalcemia occurs while receiving XGEVA, additional short-term calcium supplementation and additional monitoring may be necessary.

- Caution on risk of hypocalcemia and accompanying increases in parathyroid hormone in patients with renal impairment

- Skin infections

- Hypersensitivity reactions including anaphylaxis

- Atypical femoral fractures

- Not recommended for use in pregnant women. Women should not become pregnant during treatment and for at least 5 months after the last dose of XGEVA.

\section{For more information:}

Please consult the Product Monograph at

http://www.amgen.ca/Xgeva_PM.pdf for important information relating to adverse reactions, drug interactions, and dosing that have not been discussed here.

The Product Monograph is also available by calling Amgen Medical Information at 1-866-502-6436.

\section{Fizazi et al. study ${ }^{2}$}

Phase 3, randomized, double-blind, double-dummy, active-controlled study. Patients with castrate-resistant prostate cancer and bone metastases $(n=1901)$ received either $120 \mathrm{mg}$ XGEVA SC Q4W (once every 4 weeks) $(n=950)$ or $4 \mathrm{mg}$ zoledronic acid IV Q4W ( $n=951)$. The primary outcome measure was to demonstrate non-inferiority of time to first on-study SRE as compared to zoledronic acid. The secondary outcome measures were superiority of time to first on-study SRE and superiority of time to first and subsequent SREs. An SRE is defined as any of the following: pathologic fracture, radiation therapy to bone, surgery to bone or spinal cord compression.

References:

1. XGEVA ${ }^{\circledast}$ Product Monograph, Amgen Canada, 2015

2. Fizazi $\mathrm{K}$, et al. Denosumab versus zoledronic acid for treatment of bone metastases in men with castration-resistant prostate cancer: a randomized, double-blind study. Lancet 2011;377(9768):813-822. 